\title{
On the significance of germline cytogenetic rearrangements at MYCN locus in neuroblastoma
}

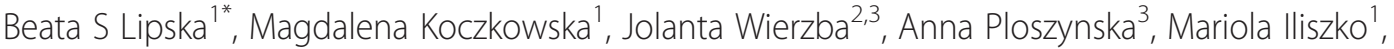 \\ Ewa Izycka-Swieszewska ${ }^{4}$, Elzbieta Adamkiewicz-Drozynska ${ }^{3}$ and Janusz Limon ${ }^{1}$
}

\begin{abstract}
Background: MYCN oncogene amplification is the most important prognostic factor in neuroblastoma. 25\% neuroblastoma tumors have somatic amplifications at this locus but little is known about its constitutional aberrations and their potential role in carcinogenesis. Here, we have performed an array-CGH and qPCR characterization of two patients with constitutional partial $2 \mathrm{p}$ trisomy including MYCN genomic region.
\end{abstract}

Results: One of the patients had congenital neuroblastoma and showed presence of minute areas of gains and losses within the common fragile site FRA2C at 2p24 encompassing MYCN. The link between 2p24 germline rearrangements and neuroblastoma development was reassessed by reviewing similar cases in the literature. Conclusions: It appears that constitutional rearrangements involving chromosome 2 p24 may play role in NB development.

Keywords: Neuroblastoma, MYCN, FRA2C, Partial 2p trisomy

\section{Background}

Congenital chromosomal aberrations have been of help in identification of causative tumor suppressor gene (TSG) in oncology, to name just two most notorious: WT1 at $11 \mathrm{p} 13.1$ and $R B 1$ at 13q14.1. Since constitutional deletions and translocations are often the first indicators of the presence of TSGs, the pursue for patients with neuroblastoma (NB) and a concomitant constitutional genomic disorder has started. Disappointingly, so far only a dozen of cases with a germinal chromosomal aberration have been reported to develop NB (Additional file 1: Table S1). Of these, only two regions were found to be affected repeatedly: a loss at chromosome $1 \mathrm{p} 36$ and a gain of chromosome $2 \mathrm{p}$. Chromosome $1 \mathrm{p} 36$ is known to be deleted in ca. $30 \%$ of primary NB tumors, being one of the most common somatic cytogenetic abnormalities of recognizable prognostic significance $[1,2]$. Accordingly, it has been proposed as the putative locus for NB TSG, however so far no major NB predisposition gene has been identified in this region [3].

\footnotetext{
* Correspondence: b.lipska@gumed.edu.pl

'Department of Biology and Genetics, Medical University of Gdansk, Debinki 1str, 80211 Gdansk, Poland

Full list of author information is available at the end of the article
}

Conversely, with respect to chromosome $2 p$ two genes involved in NB pathogenesis came into play. Germinal activating mutation in $A L K$, an oncogene lying at chromosome $2 \mathrm{p} 23$ has been recognized responsible for most of the familial NB cases, while its somatic mutations are present in $8 \%$ of sporadic tumors [4]. Then again, $2 \mathrm{p} 24.3$ is the locus of MYCN gene, amplification of which is considered the most important factor of poor prognosis in NB [5,6]. Since no clear correlation between constitutional rearrangements involving chromosome $2 \mathrm{p}$ and the role of $A L K$ and/or MYCN in early stages of NB pathogenesis has been established, in the current study we have evaluated our two cases and reviewed all reported $\mathrm{NB}$ with germinal cytogenetic rearrangements involving chromosome 2p. We used array-CGH and qPCR techniques for further delineation the minimal overlapping region, identification of the causative genes and their role in NB pathogenesis.

\section{Results}

Two patients with constitutional aberration including partial $2 p$ trisomy detected by classical cytogenetic studies were further evaluated using array-CGH. The patient with NB was found to have $20.5 \mathrm{Mb}$ duplication (arr [hg18] 2p25.3p24.1(2,999-20,462,999) ×3), while another 
patient had 22.3 Mb duplication (arr[hg18] 2p25.3p24.1 $(29,193-22,311,862) \times 3)$ at chromosome $2 p$ together with a deletion on chromosome 18q (arr[hg18] 18q22.3q23 $(71,282,999-76,112,910) \times 1)$ and $17 \mathrm{p}(\operatorname{arr}[$ hg18] $17 \mathrm{p} 13.3$ $(29,169-2,867,570) \times 1)$ respectively. In both cases region of gain encompassed $M Y C N$ genomic region but not locus of $A L K$ gene.

Evaluation of $M Y C N$ status in NB tumor was performed by FISH, array-CGH and qPCR (Figure 1). Interphase FISH showed $M Y C N$ gain nuc ish $(\mathrm{MYCN} \times 3-10)$ [60] in the tumor cells, while evaluation of metaphase chromosomes showed no signal translocation neither to dmin nor to other chromosomes. Array-CGH showed slight elevation of the $\log 2$ ratio between the blood and the tumor and three independent qPCR experiments targeting each of the $M Y C N$ exons further confirmed $M Y C N$ gain. Besides, except for the unbalanced translocation, no other segmental chromosomal alterations or regions with loss of heterozygosity $(\mathrm{LOH})$ were detected in the near-diploid tumor. $A L K$ mutation status was found not-mutated both at germinal and somatic level.

Precise delineation of the region of $M Y C N$ gain within the area of duplication has been undertaken and a series of qPCR targeting the adjacent genes have been designed. As the reference, DNA from another patient with constitutional aberration leading to partial $2 \mathrm{p}$ trisomy, namely 46,XY,der(17)t(2;17)(p24.1;p13.3) was used. Fluctuation of the gene copy number within the 15.5-19.5 Mb region of the chromosome $2 \mathrm{p}$, consistent with the boundaries of the common fragile site FRA2C has been observed both at somatic, and to lower extent also at germinal level in the NB patient. Conversely, the case without NB did not present any fluctuation of the gene copy number in the studied area (Figure 2).

\section{Discussion}

The database search for the patients with congenital chromosomal aberrations who had NB retrieved seven patients with aberrations involving chromosome $2 \mathrm{p}$ and another seven cases with rearrangements of other chromosomes (Additional file 1: Table S1). For the patients sharing the $2 \mathrm{p}$ duplication, the minimal overlapping region was estimated to encompass $1.0 \mathrm{Mb}$ at chromosome 2p24.1 (Figure 3). The region includes loci of $M Y C N, D D X 1$ and partially FAM49A gene but not $A L K$ gene. The second chromosomal region involved in the rearrangements was different in each of the $2 p$ cases reported so far. Hence it is most likely, the monosomy of the chromosome 18q22.3-q23 does not have any relevance to NB development in the child under study, especially that none of the genes mapping to this region is considered to be a cancer-related gene.

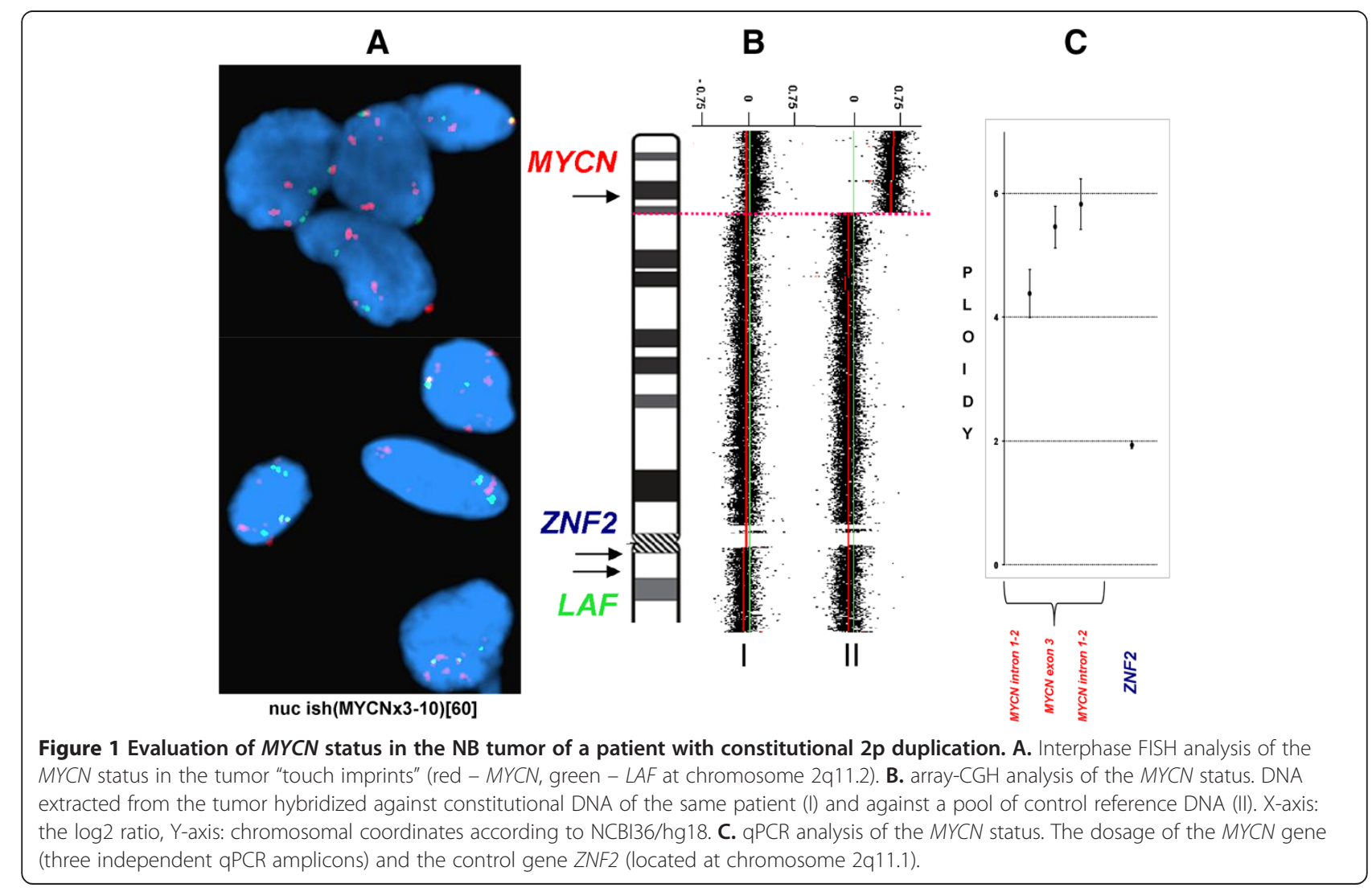




\section{Tumor}

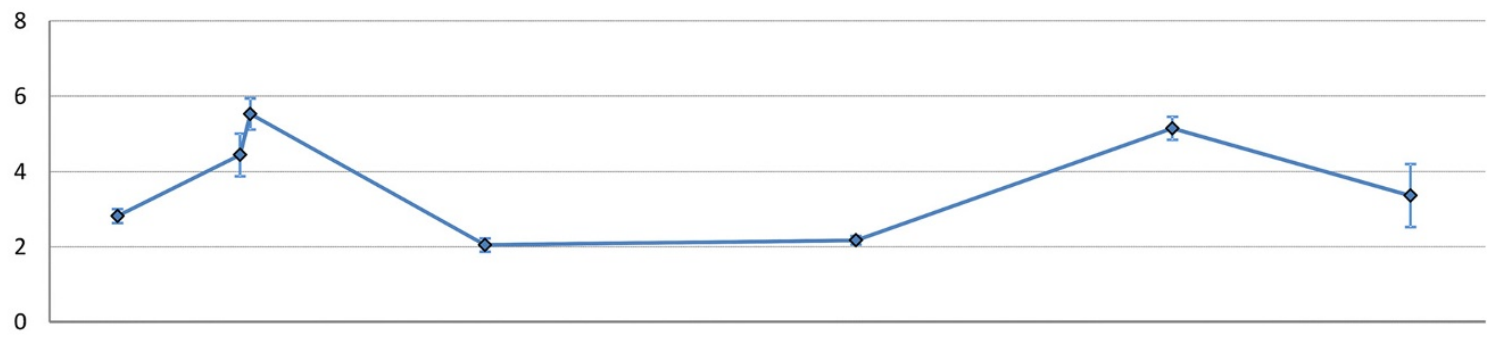

\section{Blood}

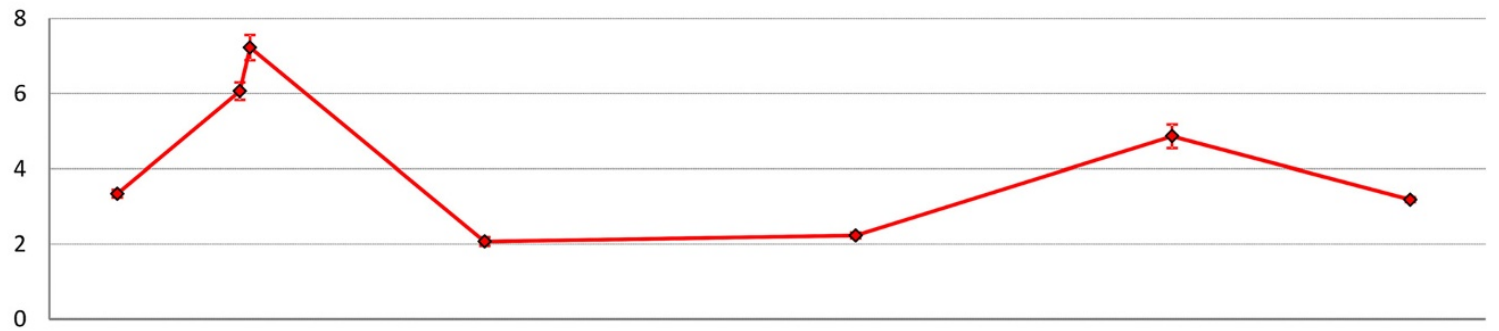

\section{Control}

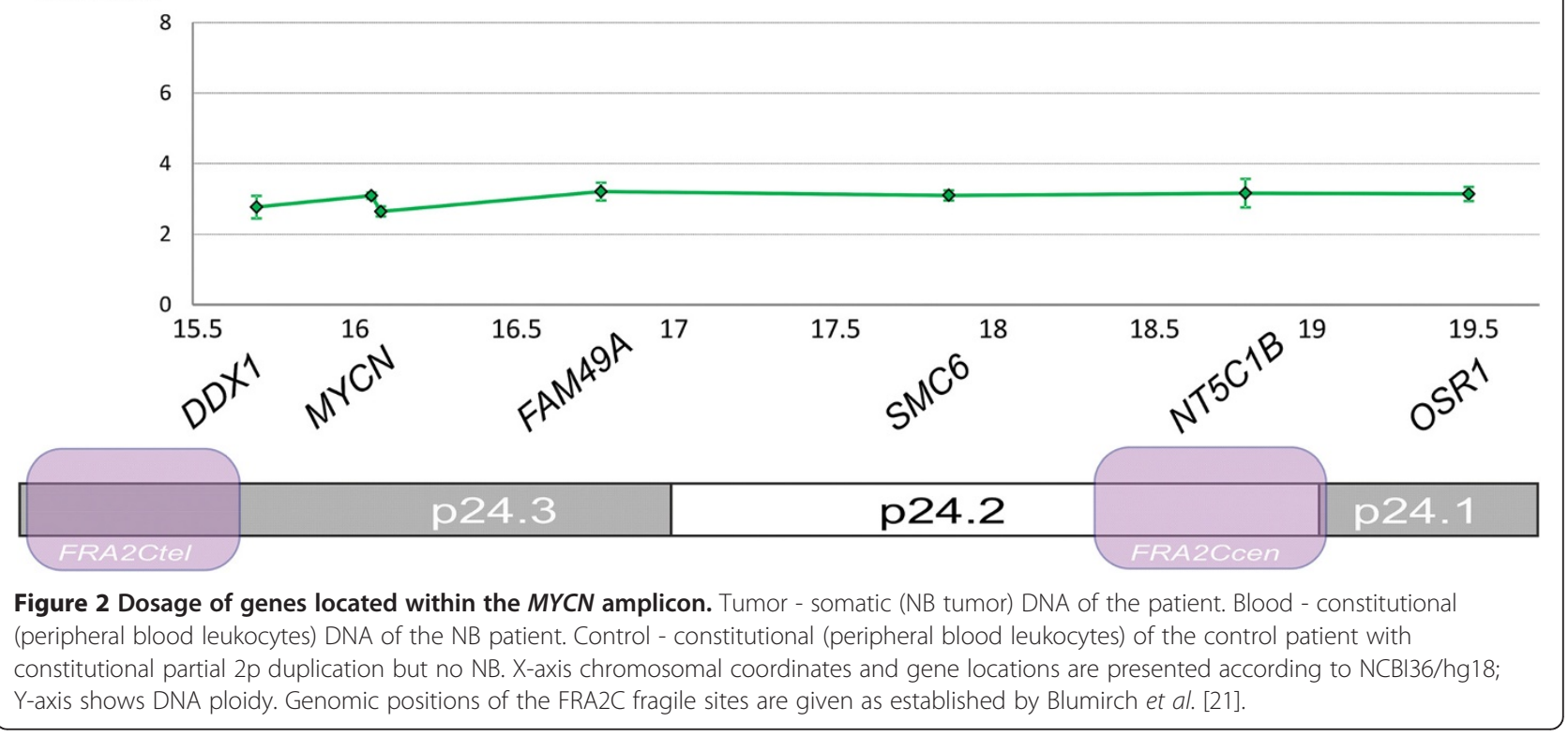

Then again, the question arises, whether constitutional $2 p$ trisomy could be considered an overt causative agent triggering NB development, since only a fraction $(<10 \%)$ of patients with constitutional $2 \mathrm{p}$ duplication eventually develops NB [7-9]. To address the issue further, we have compared two patients with constitutional rearrangement at chromosome $2 \mathrm{p}$ involving $M Y C N$ but not $A L K$ locus, of whom only one developed NB. We have found significant differences in gene copy number profile at $M Y C N$ genomic region. Areas of gains and losses at chromosome $2 \mathrm{p} 24$ were observed in the patient with NB (Figure 2). On somatic level, similar aberration, including $M Y C N$ gain, was detected in the NB sample. No other genetic event characteristic for NBs, including other segmental chromosomal aberration(s), LOHs or an $A L K$ gene point mutation was found in the tumor. Metaphase FISH studies showed uneven distribution and variable degree of the gain in single cells reflecting the heterogeneous character of the tumor. Since secondary numerical and segmental chromosomal alterations are common findings in NB, this may explain why in qPCR MYCN copy number was lower in tumor vs. blood (Figure 2) given that the assay measures relative dosage of the genes. 


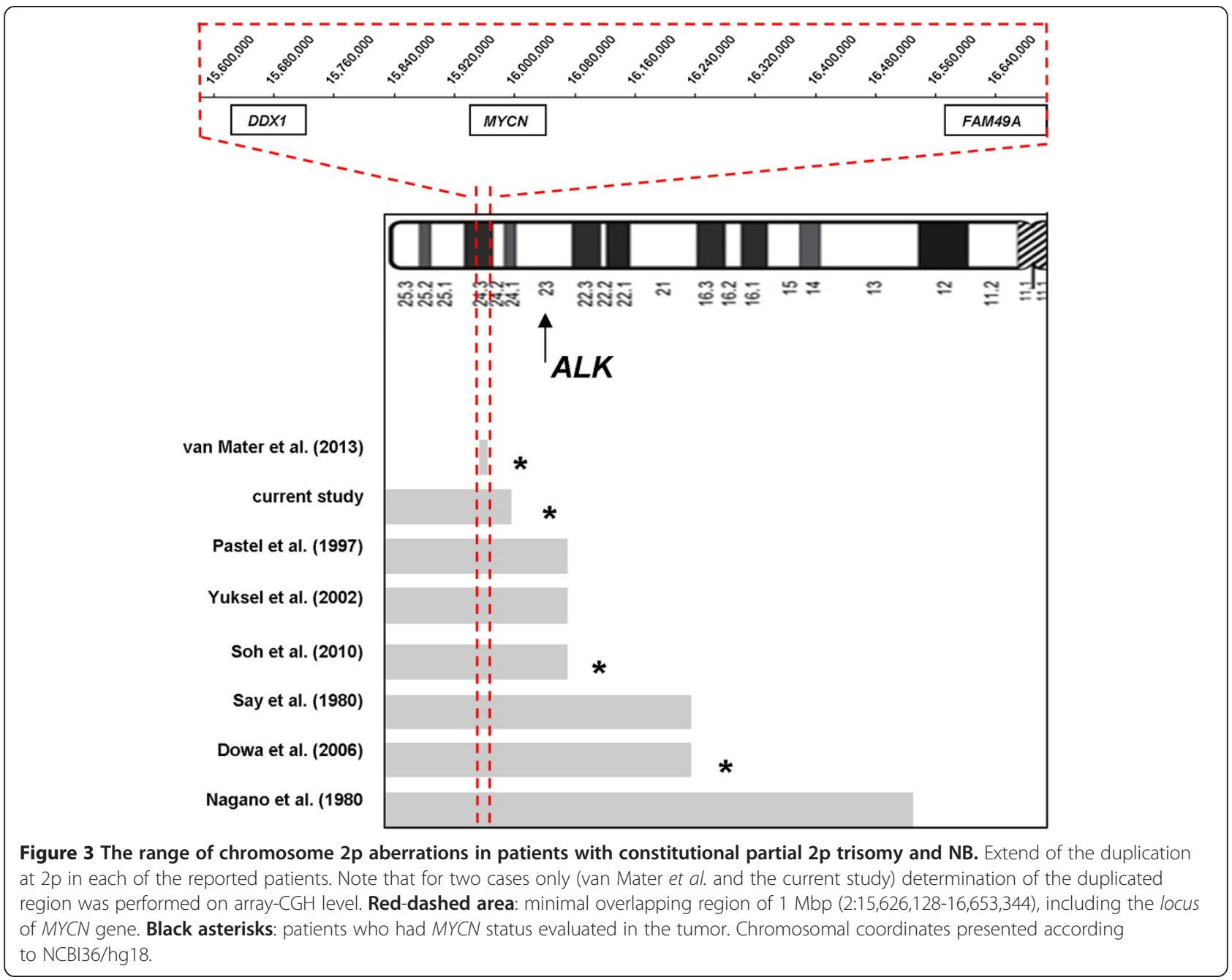

The consequence of $M Y C N$ gain in NB remains unclear. Even though large studies did not show its prognostic significance [10] our data provide further evidence in favor of its role at early stage of NB development and tumor progression. In the light of the clinical variables: low-stage, neonatal age at diagnosis, histopathology subtype and lack of adverse genetic markers our patient should have been classified as a low-risk NB. However, the uncertainty with respect to the number of $M Y C N$ gene copies, eventually classified as $M Y C N$ gain, and the natural history of other NB patients with constitutional $2 \mathrm{p}$ duplication were the two rationales for choosing an intensified strategy of treatment to address the anticipated aggressive biology of the tumor. All previously published patients with partial $2 \mathrm{p}$ trisomy who were diagnosed with $\mathrm{NB}$ over the age of six months had already progressed to metastatic disease at the time of diagnosis [9,11-13]. Unfortunately, $M Y C N$ amplification was assessed in three patients only (Figure 3). The results were discordant: a case of a stage $1 \mathrm{NB}$ was found to have 3 copies of $M Y C N$ on array-CGH [14]; a patient with stage $4 \mathrm{~S} \mathrm{NB}$ was found to have $M Y C N$ gain by FISH [15] and the third child with stage $4 \mathrm{NB}$ was found to have $M Y C N$ amplification presenting as multiple double minutes (dmin) on FISH examination [9].

The molecular evaluation of the $M Y C N$ genomic region allowed for detection of significant differences in gene copy number pattern at the $2 \mathrm{p} 24$ locus suggestive for the presence of a cryptic complex genomic rearrangement (CGG) in our NB patient. A number of models and processes have been proposed to be involved in the origin of CGGs [16]. The ongoing debate seems to favor chromothripsis, the one-off event to be responsible for most of the structural aberrations in cancer [17]. Likewise, the recent analysis of a series of patients with constitutional CGGs has shown involvement of end-joining mechanism of double-stranded DNA breaks resembling the chromothripsis-like chromosome catastrophes in their pathogenesis [18].

Moleenar et al. [19] were the first to report presence of chromothripsis in $11 \%$ of primary NBs, on the whole in older ( $>1.5$ years) patients with $M Y C N$ amplified and 
solely advanced stage tumors. In one of ten reported tumors, chromothripsis resulted in amplification and very strong overexpression of $M Y C N$. Further evaluation of high-risk NB by means of next-generation techniques has shown no recurrent fusion transcripts and presence of substantial local rearrangements in a minority of cases only [3]. The later exclusively affected the vicinity of $M Y C N$ locus, with numerous complex copy number states and retention of heterozygosity in lower-copy number regions. Such a pattern of amplified/nonamplified regions within the $M Y C N$ amplicon was already observed in a series of NB cell lines [20]. The striking common denominator for the aforesaid NB-related CGGs and the presented case is the presence of minute areas of gains and losses in the vicinity the MYCN gene. Blumirch et al. [21] have shown that the boundaries of the CGGs involving MYCN detected in NBs, and also observed in the present case, cluster to the well known microhomology region: a common fragile site FRA2C on chromosome 2p24 (Figure 2).

Common fragile sites (cFS) are evolutionarily conserved AT-rich regions inherited within normal chromosomal structure well known for their relative high mutation rate [22]. When exposed to environmental factors that interfere with DNA replication the accumulation of DNA secondary structures at cFS may give rise to double-strand breaks, what in consequence may generate structural chromosomal instability [23]. Our results suggest, that the inherited unbalanced chromosomal aberration at $2 \mathrm{p}$ may give grounds for nonrandom clustering of chromosomal breaks at the FRA2C leading to $M Y C N$ amplicon formation.

\section{Conclusions}

To our knowledge, this is the first report of a case of a constitutional genomic instability at MYCN locus detected in an neonate with an inherited unbalanced chromosomal rearrangement and neuroblastoma and no other genomic alteration and/or known NB risk factor. It seems that the germinal chromosomal aberration encompassing $M Y C N$ locus without co-involvement of $A L K$ gene was sufficient to trigger cancerogenesis.

\section{Methods}

\section{Patients}

A patient with 46,XX,der(18)t(2;18)(p24;q23)mat presenting distinct dysmorphic features (dolichocephaly, midfacial hypoplasia, large fontanella, hypotelorism, anteverted nostrils, prominent philtrium, microretrognathia), congenital defects (ASD, PDA, cervical ribs, bilateral postaxial polidactyly) and severe neonatal hypotonia was found to have a suprarenal lesion on neonatal sonography. Further image studies (MRI and metaiodobenzylguanidine (MIBG) scintiscan) as well as bone-marrow biopsy showed presence of a single solid tumor lying in the left suprarenal area, but with no sign of metastatic lesions or bonemarrow involvement. At the age of 2 months surgery was performed. In view of the final diagnosis of locoregional Schwannian stroma-poor poorly differentiated NB (low risk according to Shimada system and INRG consensus pretreatment classification) the patient started chemotherapy according to LINES 2009 (Low and Intermediate Risk Neuroblastoma European Study) protocol, however after two courses the parents declined from further oncological treatment. Moreover, after defining maternal origin of the translocation, the family refused further genetic evaluation. The patient remains alive 2.5 years later with no sign of disease recurrence.

The second patient with $46, \mathrm{XY}, \operatorname{der}(17) \mathrm{t}(2 ; 17)(\mathrm{p} 23 ; \mathrm{p} 13)$ $\mathrm{dn}$, is a mildly dysmorphic boy with multiple congenital defects including lissencephaly, cryptorchidism, duplex ureter (ureter fissus). The patient is subject to regular oncological surveillance by means of image studies and periodical testing of urine catecholamine metabolite levels. The child is alive with no sign of neoplastic process at the age of 3.8 years.

\section{DNA samples}

DNA was isolated from the peripheral blood leukocytes of two patients with constitutional partial $2 p$ trisomy and nine anonymous healthy female volunteers, which were utilized as the reference control DNA. Constitutional DNA samples used in array-CGH and qPCR experiments were isolated using QIAamp DNA Blood Midi Kit (Qiagen). Besides, tumor DNA, after verification of neoplastic cell content to be exceeding $80 \%$, was extracted from a freshfrozen neuroblastoma sample according to salting-out protocol [24].

\section{Karyotyping and fluorescent in situ hybridization}

Cytogenetic studies were performed using conventional GTG-banding of lymphocyte metaphase chromosomes at a 550 band level following standard protocol. Doublecolor fluorescent in situ hybridization (FISH) was performed on interphase nuclei of NB tumor touch imprints and on lymphocytes using Cytocell N-myc Amplification Probe LPS009 for MYCN gene copy number detection. In each analysis at least 60 nuclei were evaluated.

\section{Targeted mutational analysis of $A L K$ gene}

Germline and somatic status of $A L K$ at its mutational hot-spot (exons 23-25) was evaluated through direct sequencing (Applied Biosystem).

\section{Array comparative genomic hybrydization}

Array - CGH analysis of patients constitutional DNA and tumor DNA was at first performed using high resolution Human CGH 2.1 M Whole-Genome Tiling Array and later expanded using Human CGH 385 K 
Chromosome 2 Tiling Array and Custom CGH/LOH $37 \times 1.4$ M Arrays (NimbleGen, Roche) following the instructions provided by manufacturer. Arrays were scanned with MS200 Microarray Scanner and analyzed using NimbleScan, SignalMap and Deva v1.2.1 software (NimbleGen, Roche). All identified genomic imbalances were verified in the database of genomic variants (DGV; http://dgv.tcag.ca; last accessed May 2013).

\section{Quantitative real - time PCR}

The results of microarray study were validated by quantitative real - time PCR (qPCR) performed on LightCycler480 System (Roche). Target genes: DDX1, MYCN, FAM49A, SMC6, NT5C1B, OSR1 within the duplicated region (2p24) were assessed against a control gene ZNF2 at 2q11.2 and two reference genes GPR15 (3q11.2) and ERMP1 (9p24.1). qPCR assays were performed using FastStart Universal Probe Master and specific FAM pre - labelled probes from Universal Probe Library (Roche). All samples were run in triplicates. The dosage of target genes relative to reference genes normalized to control DNA (same as reference DNA used for array-CGH study) was assessed.

\section{Consent}

Written informed consent was obtained from the legal guardians of the patient (parents) for the publication of the data presented in the report.

\section{Additional file}

Additional file 1: Table S1. Patients with constitutional unbalanced chromosomal aberrations who developed neuroblastoma. List of all patients with constitutional chromosomal aberrations who developed neuroblastoma.

Competing interests

The authors declare that they have no competing interests.

\section{Authors' contributions}

BSL contributed to concept and design of the study, contributed to acquisition of data, designed the experiments, performed interpretation of data, performed database research and in-silico analyses and drafted the manuscript; MK - performed array-CGH and qPCR experiments and drafted the manuscript; JW - performed genetic evaluation and follow-up of the cases; AP - was primary oncologist responsible for anti-cancer treatment of the index case; $\mathrm{MI}$ - performed cytogenetical (karyotype and FISH) analyses; EIS - performed histopathological evaluation of the tumor samples and revised the draft of the manuscript critically; EAD - supervised clinical evaluation and follow-up of the cases, $J \mathrm{~L}$ - supervised cytogenetic studies and revised the draft of the manuscript critically. All authors read and approved the final manuscript.

\section{Acknowledgments}

This work has been financed by the Polish Ministry of Science and Education grant N N401 197339.

This study makes use of data generated by the DECIPHER Consortium. A full list of centres who contributed to the generation of the data is available from http://decipher.sanger.ac.uk and via email from decipher@sanger.ac.uk. Funding for the project was provided by the Wellcome Trust.

\section{Author details}

'Department of Biology and Genetics, Medical University of Gdansk, Debinki 1str, 80211 Gdansk, Poland. '2Department of General Nursery, Medical University of Gdansk, Debinki 7str, 80211 Gdansk, Poland. ${ }^{3}$ Department of Pediatrics, Hematology and Oncology, Medical University of Gdansk, Debink 7str, 80211 Gdansk, Poland. ${ }^{4}$ Laboratory of Pathology and Neuropathology, Debinki 1str, 80211 Gdansk, Poland.

Received: 19 July 2013 Accepted: 20 September 2013

Published: 16 October 2013

\section{References}

1. Schleiermacher G, Mosseri V, London WB, Maris JM, Brodeur GM, Attiyeh E, Haber M, Khan J, Nakagawara A, Speleman F, Noguera R, Tonini GP, Fischer M, Ambros I, Monclair T, Matthay KK, Ambros P, Cohn SL, Pearson AD: Segmental chromosomal alterations have prognostic impact in neuroblastoma: a report from the INRG project. Br J Cancer 2012, 107:1418-1422.

2. White PS, Thompson PM, Gotoh T, Okawa ER, Igarashi J, Kok M, Winter C, Gregory SG, Hogarty MD, Maris JM, Brodeur GM: Definition and characterization of a region of 1 p36.3 consistently deleted in neuroblastoma. Oncogene 2005, 24:2684-2694.

3. Pugh TJ, Morozova O, Attiyeh EF, Asgharzadeh S, Wei JS, Auclair D, Carter SL, Cibulskis K, Hanna M, Kiezun A, Kim J, Lawrence MS, Lichenstein L, McKenna A, Pedamallu CS, Ramos AH, Shefler E, Sivachenko A, Sougnez C, Stewart C, Ally A, Birol I, Chiu R, Corbett RD, Hirst M, Jackman SD, Kamoh B, Khodabakshi AH, Krzywinski M, Lo A, et al: The genetic landscape of high-risk neuroblastoma. Nat Genet 2013. doi: 10.1038/ng.2529.

4. Janoueix-Lerosey I, Lequin D, Brugieres L, Ribeiro A, de Pontual L, Combaret $V$, Raynal V, Puisieux A, Schleiermacher G, Pierron G, Valteau-Couanet D, Frebourg T, Michon J, Lyonnet S, Amiel J, Delattre O: Somatic and germline activating mutations of the ALK kinase receptor in neuroblastoma. Nature 2008, 455:967-970

5. Deyell RJ, Attiyeh EF: Advances in the understanding of constitutional and somatic genomic alterations in neuroblastoma. Cancer Genet 1988, 204:113-121.

6. Schwab M: MYCN in neuronal tumours. Cancer Lett 2004, 204:179-187.

7. Feenstra I, Fang J, Koolen DA, Siezen A, Evans C, Winter RM, Lees MM, Riegel M, de Vries BB, Van Ravenswaaij CM, Schinzel A: European Cytogeneticists Association Register of Unbalanced Chromosome Aberrations (ECARUCA); an online database for rare chromosome abnormalities. Eur J Med Genet 2006, 49:279-291.

8. Firth HV, Richards SM, Bevan AP, Clayton S, Corpas M, Rajan D, Van Vooren S, Moreau Y, Pettett RM, Carter NP DECIPHER: Database of chromosomal imbalance and phenotype in humans using ensembl resources. Am J Hum Genet 2009, 84:524-533.

9. van Mater D, Knelson EH, Kaiser-Rogers KA, Armstrong MB: Neuroblastoma in a pediatric patient with a microduplication of $2 \mathrm{p}$ involving the MYCN locus. Am J Med Genet 2013, 161:605-610.

10. Cohn SL, Pearson AD, London WB, Monclair T, Ambros PF, Brodeur GM, Faldum A, Hero B, lehara T, Machin D, Mosseri V, Simon T, Garaventa A, Castel V, Matthay KK, INRG Task Force: The International Neuroblastoma Risk Group (INRG) classification system: an INRG Task Force report. J Clin Oncol 2009, 10:289-297.

11. Nagano H, Kano $Y$, Kobuchi $S$, Kajitani $T$ : A case of partial $2 p$ trisomy with neuroblastoma. Jinrui Idengaku Zasshi 1980, 25:39-45.

12. Patel JS, Pearson J, Willatt L, Andrews T, Beach R, Green A: Germline duplication of chromosome 2p and neuroblastoma. J Med Genet 1997 34:949-951.

13. Yuksel A, Seven M, Karaman B, Yilmaz S, Deviren A, Hacihanefioglu S, Basaran S: Neuroblastoma in a dysmorphic girl with a partial duplication of $2 p$ caused by an unbalanced translocation. Clin Dysmorphol 2002, 11:39-42.

14. Soh SY, Stavropoulos D, Bowdin S, Thorner P, Baruchel S, Malkin D, Meyn MS, Irwin M: Metachronous neuroblastoma in an infant with constitutional unbalanced translocation $\mathrm{t}(2 ; 16)(\mathrm{p} 23 ; \mathrm{p} 13.3)$ involving ALK. Poster presentation at ANR Stockholm 2010. POC38.

15. Dowa Y, Yamamoto T, Abe Y, Kobayashi M, Hoshino R, Tanaka K, Aida N, Take H, Kato K, Tanaka Y, Ariyama J, Harada N, Matsumoto N, Kurosawa K: Congenital neuroblastoma in a patient with partial trisomy of $2 \mathrm{p}$. J Pediatr Hematol Oncol 2006, 28:379-382. 
16. Liu P, Carvalho CMB, Hastings PJ, Lupski JR: Mechanisms for recurrent and complex human genomic rearrangements. Curr Opin Genet Dev 2012, 22:211-220

17. Forment JV, Kaidi A, Jackson SP: Chromothripsis and cancer: causes and consequence of chromosome shattering. Nature Rev Cancer 2012, 12:663-670.

18. Kloosterman WP, Tavakoli-Yaraki M, van Roosmalen MJ, van Binsbergen $E$, IRenkens I, Duran K, Ballarati L, Vergult S, Giardino D, Hansson K, Ruivenkamp CA, Jager M, van Haeringen A, Ippel EF, Haaf T, Passarge E, Hochstenbach R, Menten B, Larizza L, Guryev V, Poot M, Cuppen E: Constitutional chromothripsis rearrangements involve clustered double-stranded DNA breaks and nonhomologous repair mechanisms. Cell Rep 2012, 1:648-655.

19. Molenaar JJ, Koster J, Zwijnenburg DA, van Sluis P, Valentijn $\mathrm{L}$, van der Ploeg I, Hamdi M, van Nes J, Westerman BA, van Arkel J, Ebus ME, Haneveld F, Lakeman A, Schild L, Molenaar P, Stroeken P, van Noesel MM, Ora I, Santo EE, Caron HN, Westerhout EM, Versteeg R: Sequencing of neuroblastoma identifies chromothripsis and defects in neuritogenesis genes. Nature 2012, 483:589-593.

20. Storlazzi CT, Lonoce A, Guastadisegni MC, Trombetta D, D'Addabbo P, Daniele G, L'Abbate A, Macchia G, Surace C, Kok K, Ullmann R, Purgato S, Palumbo O, Carella M, Ambros PF, Rocchi M: Gene amplification as double minutes or homogeneously staining regions in solid tumors: origin and structure. Genome Res 2010, 20:1198-1206.

21. Blumrich A, Zapatka M, Brueckner LM, Zheglo D, Schwab M, Savelyeva L: The FRA2C common fragile site maps to the borders of MYCN amplicons in neuroblastoma and is associated with gross chromosomal rearrangements in different cancers. Hum Mol Genet 2011, 20:1488-1501.

22. Yunis JJ, Soreng A: Constiutive fragile sites and cancer. Science 1984, 226:1199-1204.

23. Schwartz M, Zlotorynski E, Kerem B: The molecular basis of common and rare fragile sites. Cancer Lett 2005, 232:13-26.

24. Miller SA, Dykes DD, Polesky HF: A simple salting out procedure for extracting DNA from human nucleated cells. Nucleic Acids Res 1988, 16:1215.

doi:10.1186/1755-8166-6-43

Cite this article as: Lipska et al.: On the significance of germline

cytogenetic rearrangements at MYCN locus in neuroblastoma. Molecular Cytogenetics 2013 6:43

\section{Submit your next manuscript to BioMed Central and take full advantage of:}

- Convenient online submission

- Thorough peer review

- No space constraints or color figure charges

- Immediate publication on acceptance

- Inclusion in PubMed, CAS, Scopus and Google Scholar

- Research which is freely available for redistribution 